\title{
In-vivo study of osseointegration in Prestige LP cervical disc prosthesis
}

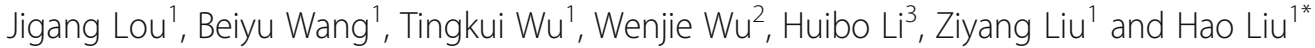

\begin{abstract}
Background: A study was designed to quantify the extent of porous osseointegration at the prosthesis-bone interface in the Prestige LP prosthesis containing a plasma-sprayed titanium coating.

Methods: Using an anterior surgical approach, cervical disc arthroplasty was performed in 8 mature male goats at the C3-C4 segment, followed by implantation of the Prestige LP prosthesis. The vertebral specimens were examined using microcomputed tomograph for histomorphometric quantification, and proceeded by routine paraffin processing for histological observation. Hence, the porous osseointegration at the prosthesis-bone interface was evaluated based on histologic and histomorphometric analyses.
\end{abstract}

Results: At 6 months after surgery, there was no evidence of prosthesis migration, loosening, subsidence, or neurologic or vascular complications. Based on gross histologic analysis, there was excellent porous ingrowth at the prosthesis-bone interface, without significant histopathologic changes. Histomorphometric analysis at the prosthesis-bone interface indicated the mean porous ingrowth of $48.5 \% \pm 10.4 \%$ and the total ingrowth range of 36.6 to $59.8 \%$.

Conclusions: As the first comprehensive in vivo investigation into the Prestige LP prosthesis, this project established a successful animal model in the evaluation of cervical disc arthroplasty. Moreover, histomorphometric analysis of porous ingrowth at the prosthesis-bone interface was more favorable for cervical disc arthroplasty with the Prestige LP prosthesis compared to historical reports of appendicular total joint arthroplasty.

Keywords: Cervical disc arthroplasty, Animal model, Porous ingrowth, Osseointegration, Histomorphometry

\section{Background}

Cervical disc arthroplasty (CDA) is an exciting new technology to treat symptomatic cervical degenerative disc disease in patients who have failed conservative care. This technology not only allows for the maintenance of normal cervical spinal motion, but also has the potential to prevent or reduce the risk of degeneration at adjacent levels, compared with the conventional fusion techniques [1-3]. However, the complications associated with CDA prostheses have been reported as heterotopic ossification, prosthesis migration and dislocation, prosthesis subsidence, spontaneous fusion, immune tissue reaction and fracture in the adjacent vertebral body $[4,5]$. Among these, the most important complication is the prosthesis migration and dislocation, because it often requires reoperation. In previous studies, the incidence

\footnotetext{
* Correspondence: liuhao110@126.com

${ }^{1}$ Department of Orthopedics, West China Hospital, Sichuan University, 37

Guoxue Road, Chengdu, Sichuan 610041, China

Full list of author information is available at the end of the article
}

of prosthesis dislocation after CDA has been reported as $0.5 \%-3.06 \%$ [6-8]. Hence, it is very essential to improve the initial stability and long-term stability of CDA prostheses in order to lower the risk of prosthesis migration and dislocation.

To date, a variety of commercial and experimental disc prostheses with various design concepts are designed to strive for better initial stability and long-term stability in order to obtain long-term survivorship of CDA prostheses. With regard to the current widely used Prestige LP prosthesis (Medtronic Sofamor Danek, Memphis, TN, USA), with two titanium ceramic composite endplates (Fig. 1), its initial device fixation is mainly attributed to the mechanisms of acute fixation achieved via a series of four rails, two on each prosthesis endplate. Besides, its long-term device fixation is acquired by a porous titanium coating on prosthesis endplate. The primary endplate bearing surface contains two layers of pure titanium, with a pore size of $75-300 \mu \mathrm{m}$, which 


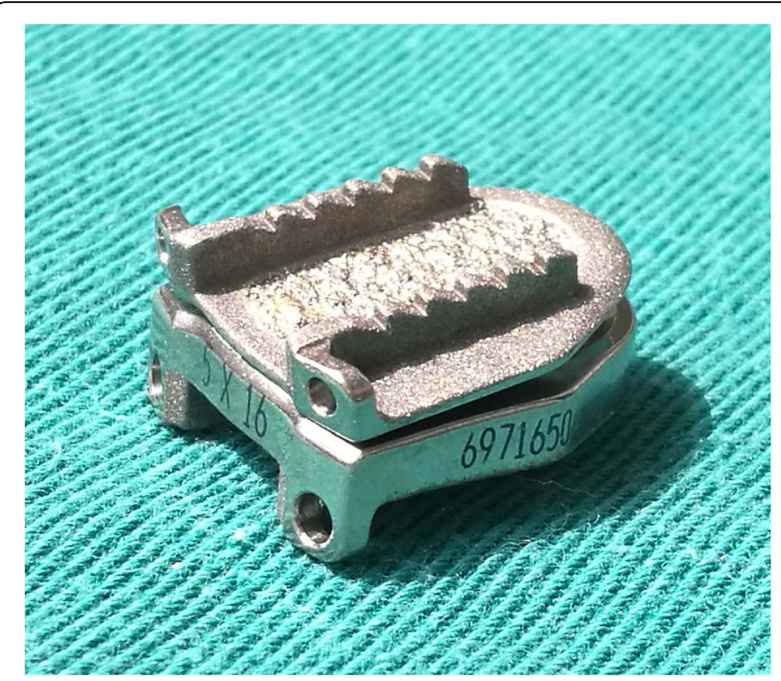

Fig. 1 The Prestige LP prosthesis contains two titanium ceramic composite endplates, with two rails on each endplate and a porous titanium plasma spray coating

serves to increase porosity and surface area and facilitate trabecular ingrowth [9]. The titanium coatings consist of a special adhesive layer $(<90 \mu \mathrm{m})$ and a cover layer $(<180 \mu \mathrm{m})$. Owing to these features, a porous titanium plasma spray coating on the endplate contacting surfaces facilitates bone ingrowth and promotes the extent of biological osseointegration at the prosthesis-bone interface, ensuring long-term stability. As it is infeasible to quantitatively evaluate the extent of porous osseointegration at the prosthesis-bone interface for patients underwent cervical disc arthroplasty, an animal model is a great alternative.

Serving as the first to demonstrate successful endplate osseointegration in the caprine cervical model, the present study was undertaken to investigate the initial stability and the biologic porous ingrowth characteristics of the Prestige LP artificial cervical disc prosthesis, with success criteria based on radiographic analysis and quantitative histomorphometry.

\section{Methods}

\section{Animal research permission}

The Institutional Animal Care and Use Committee at the West China Center of Medical Sciences, Sichuan University, Chengdu, Sichuan granted approval for this investigation. Conduct of experimentation on living animals followed the recommendations of the Guide for the Care and Use of Laboratory Animals [10], and under the close supervision of qualified and experienced persons.

\section{Animal model and surgical preparation}

Eight mature male goats (2-3 years old, mean weight $30 \mathrm{Kg}$ ) from laboratory animal center of Sichuan University were included in this study, and followed for a period of 6 months after surgery. Each animal was sedated with an intravenous injection of anesthetic medications (diazepam $0.2 \mathrm{mg} / \mathrm{kg}$ and ketamine HCL $5 \mathrm{mg} / \mathrm{kg}$ ), followed by endotracheal intubation and general inhalation anesthesia using $1 \%$ to $2 \%$ isoflurane with continuous intravenous fluids (range 3-6 mL/lb./h) administered for the duration of surgery. In addition, prophylactic intravenous antibiotics (cefazolin sodium, $1 \mathrm{~g}$ ) and analgesics (butorphanol $0.1 \mathrm{mg} / \mathrm{kg}$ ) were administered before and after surgery.

\section{Surgical technique and postoperative evaluation}

The anterior Smith-Robinson approach to the cervical spine was adapted to the goat model through a rightsided longitudinal incision with length 6- to 8- $\mathrm{cm}$, and a standard anterior cervical discectomy was performed at the $\mathrm{C} 3-\mathrm{C} 4$ intervertebral level. The endplate surfaces were prepared using curettage and a high-speed burr. According to the manufacturer's recommended tools and procedures, the Prestige LP prosthesis was then implanted at the operative disc level (Fig. 2). Blood loss, operating times, and intra- and perioperative complications were quantified.

Observations of ambulatory activities and wound healing were monitored daily, and all animals received analgesics and prophylactic antibiotics for the first 10 days postoperatively. Lateral X-ray films of the cervical spine were taken intra- and post-operatively to confirm the correct position of all disc prostheses (Fig. 3). Euthanasia was performed for each animal using an overdose $(150 \mathrm{mg} / \mathrm{kg})$ of concentrated pentobarbital solution $(390 \mathrm{mg} / \mathrm{mL})$ at 6 months after surgery. The spinal column then was carefully dissected, immediately placed in double-wrapped

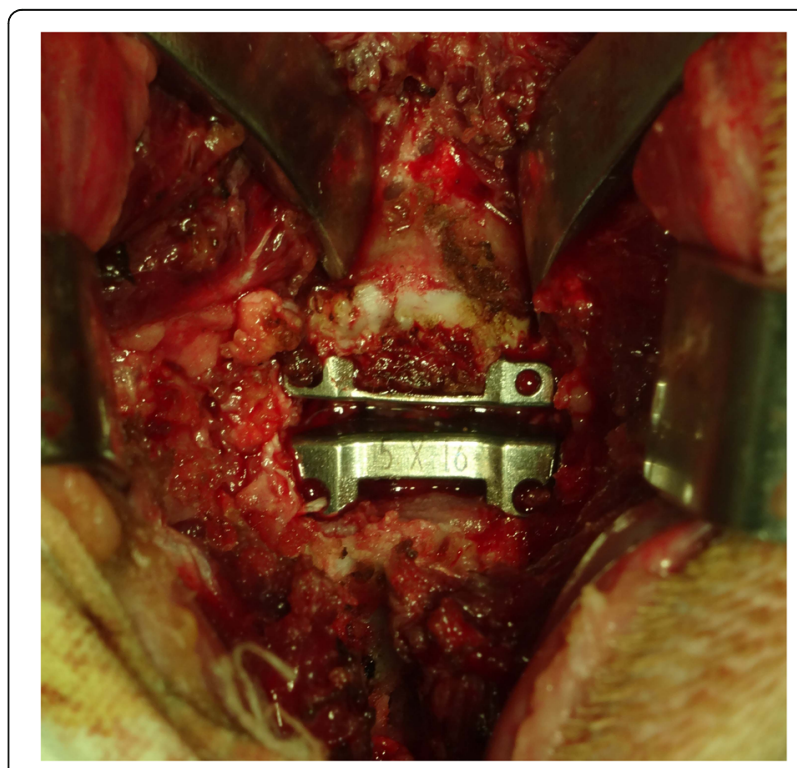

Fig. 2 Anterior intraoperative view. The Prestige LP prosthesis is implanted at the surgical level 


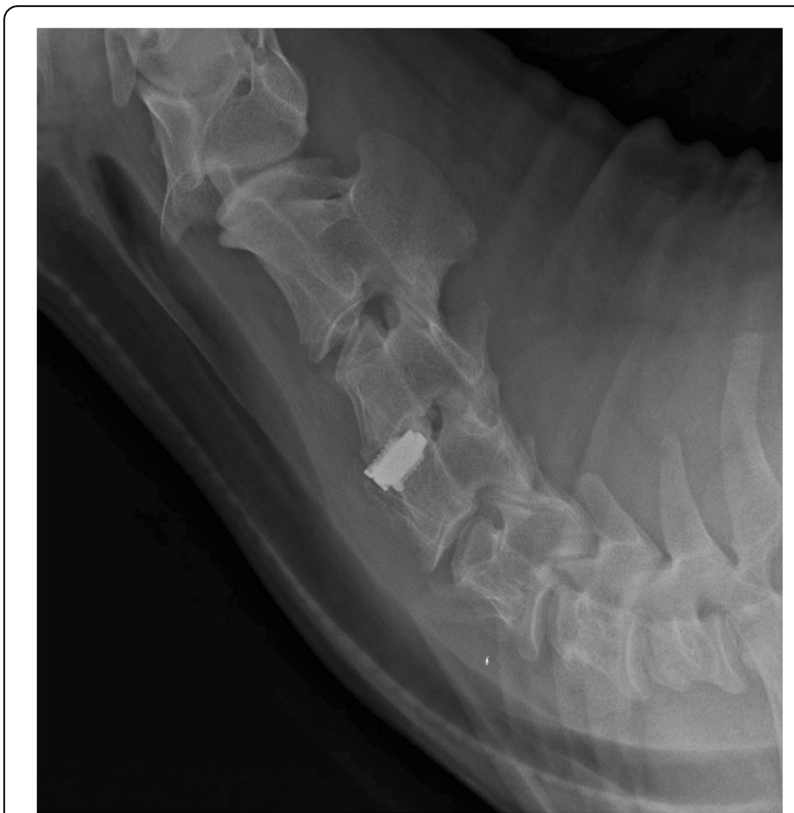

Fig. 3 Lateral X-ray film of the caprine cervical spine demonstrates that the disc prosthesis is in place

plastic specimen bags and frozen at $-20^{\circ} \mathrm{C}$ for subsequent radiographic and histological examination.

\section{Histology and histomorphometry}

The operative motion segments were examined using microcomputed tomograph (Micro-CT) to histomorphometrically quantify the percentage of trabecular ingrowth at the prosthesis-bone interface. The prosthesis surface was traced manually and expressed as a total endplate area pixel count. The regions of trabecular contact were subsequently traced, quantified in pixels, and expressed as a percentage of the total endplate area (\% ingrowth = apparent bone contact area/gross total endplate area). The above quantitative evaluation method has been widely used in several previous studies [11-15].

The vertebral specimens were then performed histological evaluation at the Biotechnology Institute Histology Laboratory of Sichuan University. The specimens were fixed in $10 \%$ neutral buffered formalin solution, then dehydrated in a series of graded alcohol which was later substituted by dimethylbenzene, and embedded in paraffin. Thereafter, the paraffin embedded sections were cut into 3-5 $\mu \mathrm{m}$ thick using thin-sectioning microtomy, and then treated with two staining techniques: standard Hematoxylin and Eosin and Masson staining.

\section{Statistical analysis}

Statistical analysis was performed using SPSS version 19.0 software (SPSS Inc., Chicago, Illinois). Histomorphometric data were presented as the percentage of trabecular bone in contact with the Prestige LP prosthesis (titanium endplates) and statistically compared with historical reports of appendicular total joint arthroplasty using an analysis of variance (ANOVA) with Student-Newman-Keuls test. All data were shown as mean \pm standard deviation, and significance was indicated at $P<0.05$.

\section{Results}

All animals survived the procedures and postoperative time period without incidence of vascular, neurologic or infectious complications. The average operating time required was $72.6 \pm 17.5 \mathrm{~min}$ (range $58-98 \mathrm{~min}$ ), with an estimated blood loss of less than $50 \mathrm{ml}$. All animals had a normal recovery by 1 week after surgery, with clinical assessment indicating normal appearance, ambulation, appetite and wound healing. Based on anteroposterior and lateral plain films, there was no evidence of prosthesis migration, loosening, or subsidence at the prosthesis-bone interface.

\section{Histomorphometry}

Micro-CT of the operative motion segments showed excellent osseointegration at the prosthesis-bone interface (Fig. 4a and b). Histomorphometric analysis at the prosthesis-bone interface (apparent bone contact area/ gross total endplate area) indicated that the mean porous ingrowth was $48.5 \% \pm 10.4 \%$ (total range: $36.6 \%$ to $59.8 \%$ ) at 6 months after surgery, which was higher than that reported for acetabular components, tibial plateaus, and femoral stem components found in the appendicular skeleton (Fig. 5).

\section{Bone histology}

As an overall statement, gross histologic analysis of the Prestige LP prosthesis demonstrated excellent ingrowth at the prosthesis-bone interface, without evidence of particulate wear debris or significant histopathologic changes. All the vertebral specimens were fixed and underwent routine paraffin processing and slide preparation. The paraffin embedded sections were cut, slide mounted, and stained using standard Hematoxylin and Eosin and Masson staining. As a result, there were both plenty of proliferated osteoblasts and regenerated osseous tissues in some regions of the prosthesis-bone interface. Moreover, there was a distinct interface between regenerated osseous tissues and mature bone tissues. (Fig. 6a and b).

\section{Discussion}

To date, a wide variety of commercial and experimental artificial prosthetic discs are now available on the market or are under clinical trial. Despite with different design concepts, all artificial cervical discs are designed to replace the diseased intervertebral discs to perform their functions. The successful outcome of cervical disc 

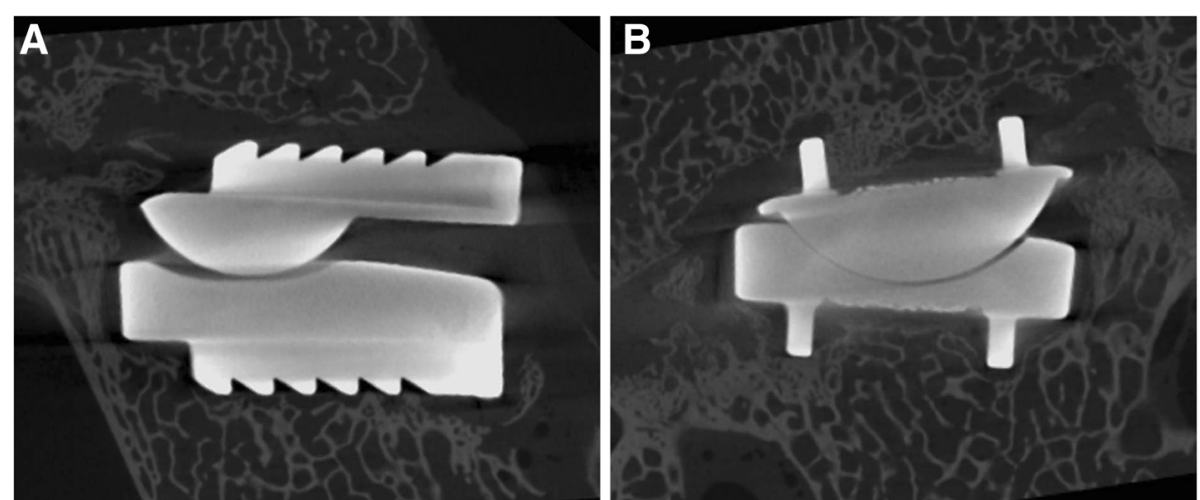

Fig. 4 Microcomputed tomograph of the operative segment. Excellent ingrowth is seen at the prosthesis-bone interface at 6 months after surgery in the mid-sagittal plane (a) and specified-coronal plane (b)

replacement, on one hand, rests upon the mechanisms of acute fixation, which are accomplished by endplate modifications involving the use of keels, teeth, rails, and serrations providing initial device fixation [16], on the other hand, depends on the extent of biological osseointegration at the prosthesis-bone interface, ensuring longterm device fixation. Therefore, as a current widely used artificial disc, it is very essential to evaluate the initial stability and the biological porous ingrowth characteristics of the Prestige LP prosthesis.

In the current study, radiographic analysis showed no evidence of prosthesis migration, loosening, or subsidence. Most importantly and most challenging is for device to encourage osseointegration at the prosthesisbone interface in order to minimize the incidence of clinical device loosening or migration after CDA. Based on the histomorphometry data, the mean porous ingrowth was $48.5 \% \pm 10.4 \%$. This demonstrated excellent porous osseointegration at the prosthesis-bone interface for the Prestige LP prosthesis, similar to that reported in several previous studies [13-15]. Moreover, the mean porous ingrowth was much higher than that reported for porous ingrowth found in appendicular total joint arthroplasty (only $20 \%-30 \%$ ingrowth). Harvey et al. [17] found the values of bone ingrowth to be $9.7 \pm 5.38 \%$ for a composite stem compared with $28.1 \pm 5.31 \%$ for a titanium alloy stem in a canine total hip arthroplasty model. Jasty et al. [18] retrieved five porous-coated femoral components from patients underwent revision arthroplasty, and found the ingrowth was 4 to $44 \%$ (mean 24\%). Sumner et al. $[19,20]$ investigated the uncemented femoral components at 2 years in a canine total hip arthroplasty model, and found the mean ingrowth to be $32.7 \pm 4.7 \%$ (range 19.7-47.5\%) with fiber metal coatings compared with

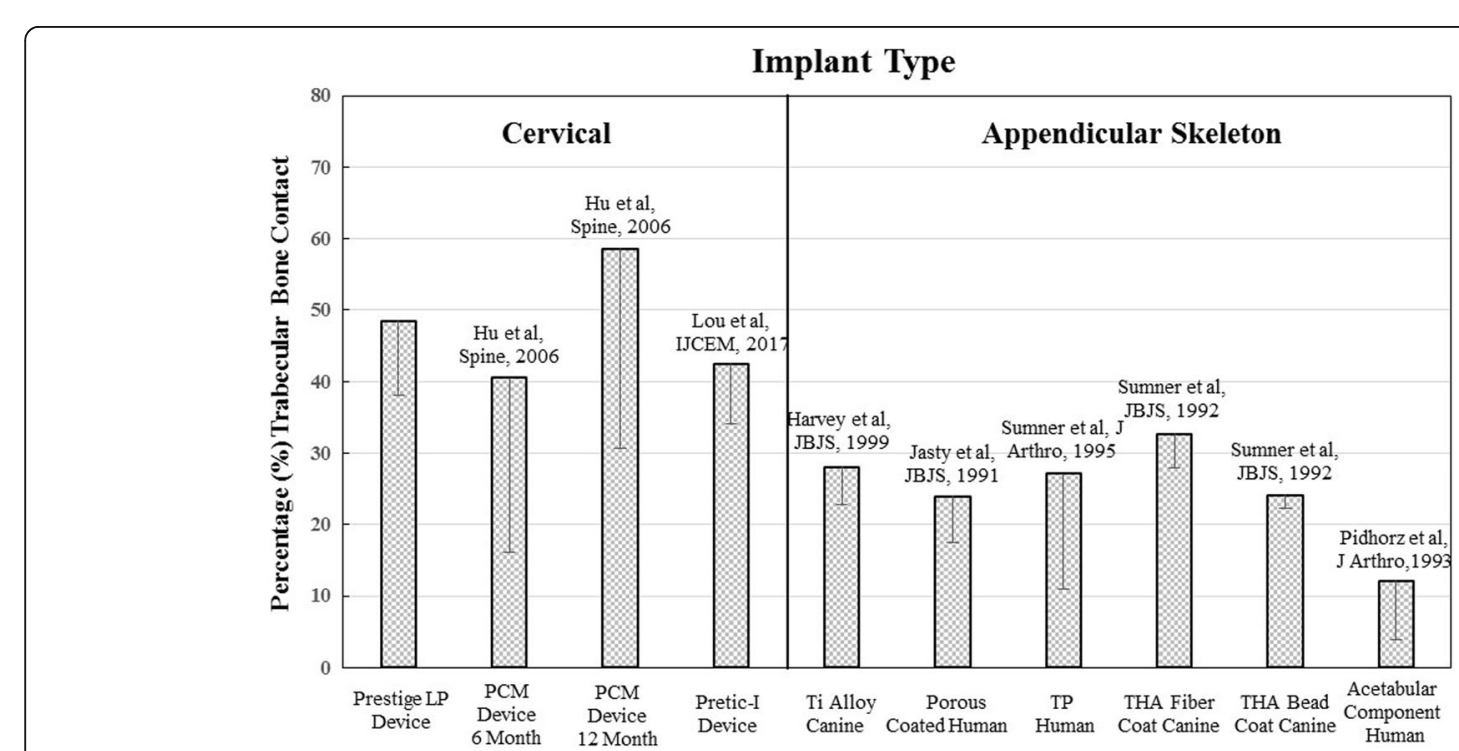

Fig. 5 Porous ingrowth. Percentage of ingrowth-bone contact on the endplate surface. The bar graph compares porous ingrowth in cervical disc arthroplasty and appendicular total joint arthroplasty 


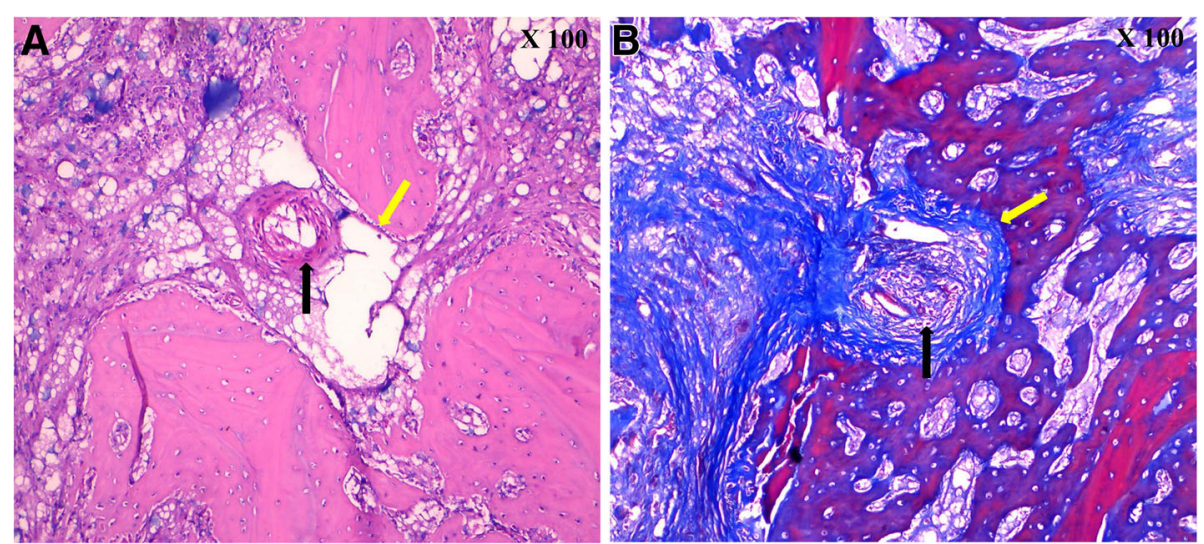

Fig. 6 Sections using standard Hematoxylin and Eosin stain (a), Sections using Masson stain (b). The proliferated osteoblasts (black arrow). The interface between regenerated osseous tissues and mature bone tissues (yellow arrow)

$24.1 \pm 1.8 \%$ (range 19.0-31.2\%) using bead coatings. Pidhorz et al. [21] retrieved 11 cementless acetabular components at autopsy at an average of 41 months (5 weeks to 75 months) after surgery, with mean ingrowth of $12.1 \pm 8.2 \%$. As for the improved extent of porous ingrowth in the Prestige LP prosthesis, one reason may be that the rails provide a better primary press-fit fixation, facing toward the bony endplates to resist pull-out, and the porous titanium plasma spray coating facilitates bone ingrowth and significantly encourages osseointegration at the prosthesis-bone interface in the long run. In addition, we postulate that the more favorable porous ingrowth may be the result of acute ligamentotaxis causing long-term and sustained compression across the prosthesis-bone interface.

There is controversy regarding the most accurate method of measuring the porous ingrowth of cementless prostheses [22-24]. The three most widely used methods are microradiography, stained histology, and backscattered electron imaging-scanning electron microscopy (BEI-SEM). In this study, we adopted microradiography and stained histology to evaluate the porous ingrowth at the prosthesis-bone interface. It turned out that there was evidence of excellent osseointegration at the prosthesis-bone interface. Sumner et al. [25] compared the porous ingrowth of acetabular cups using the three methods, finding that BEI-SEM and histologic sections possessed comparable results, whereas microradiography underestimated the porosity of the porous coating by a mean of $17 \%$ and simultaneously overestimated the amount of bony ingrowth by a mean of $0.8 \%$.

There are still some aspects need to be improved in the current study. First, the caprine model used only a 6-month follow-up period and a small sample size. It is expected that longer follow-up evaluation with greater numbers of subjects would be required to obtain a more reliable measure of the biological osseointegration of
CDA with the Prestige LP prosthesis. In addition, it is a relatively simplified design for the Prestige LP prosthesis with a porous titanium plasma spray coating. A unique bioactive TiCaPHA (titanium/calcium phosphate/hydroxyapatite) coating is more favorable to encourage osseointegration at the prosthesis-bone interface $[13,14]$. Moreover, the prosthesis may possess stronger surface and more favorable porous osseointegration through the procedure for an electrochemically bonded coating than a plasma-sprayed coating [12].

\section{Conclusions}

In summary, as the first comprehensive in vivo investigation into the Prestige LP prosthesis, the present project established a successful animal model for CDA. Moreover, histomorphometric analysis of porous ingrowth at the prosthesis-bone interface was more favorable for CDA with the Prestige LP prosthesis, compared to historical reports of appendicular total joint arthroplasty.

\section{Additional file}

Additional file 1: The original data on the Micro- $\mathrm{CT}$ of the operative segments in a caprine cervical disc arthroplasty model. (DOCX $16 \mathrm{~kb}$ )

\section{Abbreviations}

BEI-SEM: Backscattered electron imaging-scanning electron microscopy; CDA: Cervical disc arthroplasty; Micro-CT: Microcomputed tomograph; TiCaPHA: Titanium/calcium phosphate/hydroxyapatite

\section{Acknowledgements}

We would like to thank Dr. Li Tian for her highly valuable participation in animal care and operations.

\section{Funding}

This study was supported by the foundation of Science \& Technology Department of Sichuan Province (grant No. 0040205301 C35), PR China.

\section{Availability of data and materials}

The dataset supporting the conclusions of this article is included within the (Additional file 1). 


\section{Authors' contributions}

$H \mathrm{~L}, J \mathrm{~L}, \mathrm{BW}, \mathrm{WW}$, and $\mathrm{HL}$ conceived and designed the experiments. TW and $\mathrm{ZL}$ analyzed the data. $\mathrm{HL}$ and $J \mathrm{~L}$ wrote the paper. All authors read and approved the final manuscript.

\section{Ethics approval}

This study was approved by the Institutional Animal Care and Use Committee at the West China Center of Medical Sciences, Sichuan University, Chengdu, Sichuan, China.

\section{Consent for publication}

Not applicable.

\section{Competing interests}

The authors declare that they have no competing interests.

\section{Publisher's Note}

Springer Nature remains neutral with regard to jurisdictional claims in published maps and institutional affiliations.

\section{Author details}

'Department of Orthopedics, West China Hospital, Sichuan University, 37 Guoxue Road, Chengdu, Sichuan 610041, China. ${ }^{2}$ Department of Orthopedics, Southwest Hospital, the Third Military Medical University, Chongqing, China. ${ }^{3}$ Department of Orthopedics, Qianfoshan Hospital, Shandong University, Jinan, Shandong, China.

\section{Received: 22 October 2017 Accepted: 30 January 2018}

\section{Published online: 07 February 2018}

\section{References}

1. Sasso RC, Smucker JD, Hacker RJ, Heller JG. Artificial disc versus fusion: a prospective, randomized study with 2-year follow-up on 99 patients. Spine (Phila Pa 1976). 2007;32:2933-40.

2. Phillips FM, Allen TR, Regan JJ, Albert TJ, Cappuccino A, Devine JG, et al. Cervical disc replacement in patients with and without previous adjacent level fusion surgery: a prospective study. Spine (Phila Pa 1976). 2009;34:556-65.

3. Maldonado CV, Paz RD, Martin CB. Adjacent-level degeneration after cervical disc arthroplasty versus fusion. Eur Spine J. 2011;20(Suppl 3):403-7.

4. Cavanaugh DA, Nunley PD, Kerr EJ 3rd, Werner DJ, Jawahar A. Delayed hyper-reactivity to metal ions after cervical disc arthroplasty: a case report and literature review. Spine (Phila Pa 1976). 2009;34:E262-5.

5. Thaler M, Hartmann S, Gstöttner M, Lechner R, Gabl M, Bach C. Footprint mismatch in total cervical disc arthroplasty. Eur Spine J. 2013:22:759-65.

6. Goffin J, Van Calenbergh F, van Loon J, Casey A, Kehr P, Liebig K, et al. Intermediate follow-up after treatment of degenerative disc disease with the Bryan cervical disc prosthesis: single-level and bi-level. Spine (Phila Pa 1976). 2003:28:2673-8.

7. Anderson PA, Sasso RC, Riew KD. Comparison of adverse events between the Bryan artificial cervical disc and anterior cervical arthrodesis. Spine (Phila Pa 1976). 2008:33:1305-12.

8. Ozbek Z, Ozkara E, Arslantas A. Implant migration in cervical disk Arthroplasty. World Neurosurg. 2017;97:390-7.

9. Rahbek O, Overgaard S, Jensen TB, Bendix K, Søballe K. Sealing effect of hydroxyapatite coating: a 12-month study in canines. Acta Orthop Scand. 2000;71:563-73

10. Mason TJ, Matthews M. Aquatic environment, housing, and management in the eighth edition of the guide for the care and use of laboratory animals: additional considerations and recommendations. J Am Assoc Lab Anim Sci. 2012;51:329-32

11. Cunningham BW, Lowery GL, Serhan HA, Dmitriev AE, Orbegoso CM, McAfee PC, et al. Total disc replacement arthroplasty using the AcroFlex lumbar disc: a non-human primate model. Eur Spine J. 2002; 11(Suppl 2):S115-23.

12. MCAfee PC, Cunningham BW, Orbegoso CM, Sefter JC, Dmitriev AE, Fedder IL. Analysis of porous ingrowth in intervertebral disc prostheses: a nonhuman primate model. Spine (Phila Pa 1976). 2003;28:332-40.

13. Hu N, Cunningham BW, McAfee PC, Kim SW, Sefter JC, Cappuccino A, et al. Porous coated motion cervical disc replacement: a biomechanical, histomorphometric, and biologic wear analysis in a caprine model. Spine (Phila Pa 1976). 2006;31:1666-73.
14. Cunningham BW, Hu N, Zorn CM, McAfee PC. Bioactive titanium calcium phosphate coating for disc arthroplasty: analysis of 58 vertebral end plates after 6- to 12-month implantation. Spine J. 2009;9:836-45.

15. Lou J, Wu W, Li H, Wang B, Liu H. Analysis of bony ingrowth in novel cervical disc prosthesis. Int J Clin Exp Med. 2017;10:10196-201.

16. Cunningham BW, Hu N, Zorn CM, McAfee PC. Comparative fixation methods of cervical disc arthroplasty versus conventional methods of anterior cervical arthrodesis: serration, teeth, keels, or screws? J Neurosurg Spine. 2010;12:214-20.

17. Harvey EJ, Bobyn JD, Tanzer M, Stackpool GJ, Krygier JJ, Hacking SA. Effect of flexibility of the femoral stem on bone-remodeling and fixation of the stem in a canine total hip arthroplasty model without cement. J Bone Joint Surg Am. 1999;81:93-107.

18. Jasty M, Bragdon CR, Maloney WJ, Haire T, Harris WH. Ingrowth of bone in failed fixation of porous-coated femoral components. J Bone Joint Surg Am. 1991;73:1331-7

19. Sumner DR, Turner TM, Urban RM, Galante JO. Remodeling and ingrowth of bone at two years in a canine cementless total hip-arthroplasty model. J Bone Joint Surg Am. 1992;74:239-50.

20. Sumner DR, Kienapfel H, Jacobs JJ, Urban RM, Turner TM, Galante JO. Bone ingrowth and wear debris in well-fixed cementless porous-coated tibial components removed from patients. J Arthroplast. 1995;10:157-67.

21. Pidhorz LE, Urban RM, Jacobs JJ, Sumner DR, Galante JO. A quantitative study of bone and soft tissues in cementless porous-coated acetabular components retrieved at autopsy. J Arthroplast. 1993;8:213-25.

22. Engh CA, Zettl-Schaffer KF, Kukita Y, Sweet D, Jasty M, Bragdon C. Histological and radiographic assessment of well functioning porous-coated acetabular components. A human postmortem retrieval study. J Bone Joint Surg Am. 1993;75:814-24.

23. Urban RM, Jacobs JJ, Sumner DR, Peters CL, Voss FR, Galante JO. The boneimplant interface of femoral stems with non-circumferential porous coating J Bone Joint Surg Am. 1996;78:1068-81.

24. Bloebaum RD, Rhodes DM, Rubman MH, Hofmann AA. Bilateral tibial components of different cementless designs and materials. Microradiographic, backscattered imaging, and histologic analysis. Clin Orthop Relat Res. 1991;268:179-87.

25. Sumner DR, Bryan JM, Urban RM, Kuszak JR. Measuring the volume fraction of bone ingrowth: a comparison of three techniques. J Orthop Res. 1990;8:448-52.

\section{Submit your next manuscript to BioMed Central and we will help you at every step:}

- We accept pre-submission inquiries

- Our selector tool helps you to find the most relevant journal

- We provide round the clock customer support

- Convenient online submission

- Thorough peer review

- Inclusion in PubMed and all major indexing services

- Maximum visibility for your research

Submit your manuscript at www.biomedcentral.com/submit
Biomed Central 